Buletin Ilmiah Mat. Stat. dan Terapannya (Bimaster)

Volume 09, No. 1 (2020), hal 79-86.

\title{
PERAMALAN VOLATILITAS SAHAM MENGGUNAKAN MODEL THRESHOLD GENERALIZED AUTOREGRESSIVE CONDITIONAL HETEROSCEDASTICITY
}

\author{
Ervina, Dadan Kusnandar, Nurfitri Imro’ah
}

\begin{abstract}
INTISARI
Model Threshold Generalized Autoregressive Conditional Heteroscedasticity (TGARCH) merupakan model yang digunakan untuk memodelkan volatilitas yang memiliki efek asimetris. Tujuan penelitian ini adalah memodelkan dan meramalkan volatilitas IHSG menggunakan model TGARCH untuk sepuluh periode ke depan. Data yang digunakan adalah data return IHSG penutupan mingguan dari tanggal 8 Februari 2009 sampai dengan 10 Februari 2019. Penelitian ini diawali dengan pembentukan model Box Jenkins. Residual model Box Jenkins terbaik digunakan untuk mendeteksi heteroskedastisitas menggunakan uji ARCH-LM. Data residual yang memiliki heteroskedastisitas dimodelkan ke dalam model GARCH. Residual model GARCH dan residual model Box Jenkins digunakan untuk memeriksa pengaruh asimetris, yaitu dengan melakukan korelasi silang pada kedua residual model tersebut. Berdasarkan hasil korelasi silang yang dilakukan didapatkan adanya pengaruh asimetris terhadap volatilitas, sehingga digunakan model TGARCH untuk mengatasinya. Model TGARCH terbaik dalam penelitian ini adalah TGARCH(1,1) berdasarkan nilai Akaike Information Criterion (AIC) dan Schwarz Criterion (SC) terkecil. Model TGARCH(1,1) digunakan untuk meramalkan volatilitas IHSG. Hasil peramalan volatilitas yang diperoleh untuk sepuluh periode ke depan mengalami peningkatan sebesar 0,000015 sampai dengan 0,000029.
\end{abstract}

Kata Kunci: Asimetris, GARCH, TGARCH

\section{PENDAHULUAN}

Saham merupakan contoh aset finansial yang digunakan untuk berinvestasi, yang berupa data runtun waktu seperti harian, mingguan, bulanan dan tahunan. Dalam berinvestasi investor perlu memperhatikan tingkat return dan tingkat risiko. Risiko dapat diukur dengan volatilitas return saham. Volatilitas didefinisikan sebagai fluktuasi dari return-return suatu saham pada periode tertentu. Adanya volatilitas akan menyebabkan risiko dan ketidakpastian yang dihadapi investor semakin besar. Investor dapat mengontrol dan mengurangi risiko pasar dari aset-aset yang diperdagangkan seperti saham, dengan cara memperkirakan pergerakan harga saham melalui proses pemodelan [1].

Keberadaan volatilitas memunculkan permasalahan heteroskedastisitas pada varians residual. Data runtun waktu yang memiliki heteroskedastisitas dapat dimodelkan menggunakan model Generalized Autoregressive Conditional Heteroscedasticity (GARCH) [2]. Model GARCH digunakan untuk memodelkan data runtun waktu yang memiliki pengaruh simetris pada volatilitasnya. Namun, return saham memiliki pengaruh yang asimetris pada volatilitasnya. Oleh karena itu, dikembangkan suatu model yang digunakan untuk memperbaiki kelemahan dari model ARCH dan GARCH yaitu Threshold Generalized Autoregressive Conditional Heteroscedasticity (TGARCH). Model TGARCH merupakan model yang digunakan untuk memodelkan data runtun waktu yang memiliki pengaruh asimetris pada volatilitasnya [3].

Tujuan penelitian ini adalah menganalisis dan menentukan hasil peramalan volatilitas saham menggunakan model TGARCH untuk sepuluh periode ke depan. Data yang digunakan adalah data IHSG mingguan dari tanggal 8 Februari 2009 sampai dengan 10 Februari 2019. Data yang diolah merupakan return saham. Return saham diuji stasioneritas menggunakan uji Augmented Dickey Fuller (ADF) dan dimodelkan dalam model Box Jenkins. Kemudian residual dari model Box Jenkins yang terbaik diuji untuk melihat adanya heteroskedastisitas dengan menggunakan uji ARCH Lagrange Multiplier (ARCH-LM). Apabila terdapat heteroskedastisitas maka return saham dimodelkan ke 
dalam model GARCH dan diuji pengaruh asimetris. Selanjutnya uji asimetris dilakukan pada residual kuadrat model Box Jenkins yang terbaik dengan residual model GARCH terbaik menggunakan korelasi silang. Jika tidak terdapat pengaruh asimetris maka menggunakan model GARCH, jika terdapat pengaruh asimetris maka menggunakan model TGARCH. Langkah terakhir meramalkan volatilitas saham sepuluh periode ke depan menggunakan model TGARCH yang terbaik.

\section{RETURN DAN VOLATILITAS SAHAM}

Return harga saham merupakan tingkat pengembalian pendapatan yang diterima dari suatu investasi. Return harga saham dapat dirumuskan sebagai berikut [4]:

$$
r_{t}=\ln \frac{P_{t}}{P_{t-1}}
$$

dengan $r_{t}$ adalah return saham pada waktu ke- $t$ dan $P_{t}$ adalah harga saham suatu pasar pada waktu ke- $t$.

Volatilitas merupakan ukuran statistik penyebaran return dari suatu saham yang bisa diukur dengan standar deviasi atau variansi. Secara umum volatilitas di pasar keuangan mencerminkan tingkat ketidakpastian atau risiko atas besaran perubahan nilai suatu saham. Volatilitas dapat dihitung menggunakan rumus standar deviasi sebagai berikut [5].

$$
\sigma_{t}=\sqrt{\frac{\sum_{t=1}^{n}\left(r_{t}-\bar{r}\right)^{2}}{n-1}}
$$

dengan $r_{t}$ adalah return saham pada waktu ke- $t$ dan $\bar{r}$ adalah nilai rata-rata dari return.

\section{UJI ARCH LAGRANGE MULTIPLIER (ARCH-LM)}

Data runtun waktu yang mengandung masalah heteroskedastisitas dapat dideteksi dengan uji ARCH-LM [6]. Hipotesis dalam pengujian ARCH-LM adalah sebagai berikut:

$H_{0}$ : tidak terdapat heteroskedastisitas

$H_{1}$ : terdapat heteroskedastisitas

Statistik uji: $\quad F=\frac{\left(S S R_{0}-S S R_{1}\right) / u}{S S R_{1} /(n-2 u-1)}$

dimana $S S R_{0}=\sum_{u+1}^{n}\left(\varepsilon_{t}^{2}-\bar{\varepsilon}\right)^{2} ; S S R_{1}=\sum_{u+1}^{n} \hat{e}_{t}^{2} ; u$ adalah orde pada model ARCH; $n$ adalah jumlah observasi; $\bar{\varepsilon}$ adalah rata-rata dari $\varepsilon_{t}^{2}$; $\hat{e}_{t}^{2}$ adalah residual kuadrat terkecil. Kriteria pengujian adalah $H_{0}$ ditolak jika nilai probabilitas dari $F<\alpha$.

\section{AKAIKE INFORMATION CRITERION (AIC) DAN SCHWARZ CRITERION (SC)}

Kriteria pemilihan model terbaik dapat dilakukan menggunakan metode AIC dan SC yang dapat dirumuskan sebagai berikut [7]:

$$
\begin{aligned}
& A I C=-2\left(\frac{l}{n}\right)+2\left(\frac{v}{n}\right) \\
& S C=-2\left(\frac{l}{n}\right)+\frac{v \log (n)}{n}
\end{aligned}
$$

$\operatorname{dimana} l=-\frac{n m}{2}(1+\log 2 \pi)-\frac{n}{2} \log |\widehat{\Omega}| \operatorname{dengan}|\widehat{\Omega}|=\operatorname{det}\left(\sum \hat{\varepsilon} \hat{\varepsilon}^{\prime} / n\right)$

dengan $v$ adalah jumlah parameter yang diestimasi, $m$ adalah jumlah persamaan dan $n$ adalah jumlah observasi. 


\section{MODEL GENERALIZED AUTOREGRESSIVE CONDITIONAL HETEROSCEDASTICITY (GARCH)}

Model GARCH merupakan generalisasi dari model ARCH [2]. Dalam model GARCH, varians residual tidak hanya dipengaruhi oleh residual periode lalu tetapi juga oleh varians residual periode yang lalu. Bentuk umum model $\operatorname{GARCH}(u, s)$ adalah

$$
\sigma_{t}^{2}=\omega+\sum_{i=1}^{u} \alpha_{i} \varepsilon_{t-i}^{2}+\sum_{j=1}^{s} \beta_{j} \sigma_{t-j}^{2}
$$

dengan $\omega$ adalah konstanta; $\beta_{j}$ adalah parameter GARCH ke- $j ; a_{i}$ adalah parameter ARCH ke- $i ; \varepsilon_{t-i}$ adalah residual pada waktu $t-i$. Jika $s=0$, maka diperoleh model ARCH. Koefisien-koefisien dari model $\operatorname{GARCH}(u, s)$ bersifat sebagai berikut [8]:

(1) $\omega>0$

(2) $a_{i} \geq 0$, untuk $\mathrm{i}=1,2, \ldots, u$

(3) $\beta_{j} \geq 0$, untuk $\mathrm{j}=1,2, \ldots, s$

(4) $\sum_{i=1}^{u} \sum_{j=1}^{s}\left(a_{i}+\beta_{j}\right)<1$

\section{UJI PENGARUH ASIMETRIS}

Good news berarti informasi akan berdampak positif terhadap pergerakan volatilitas yaitu kenaikan pada harga saham. Bad news berarti informasi akan berdampak negatif terhadap pergerakan volatilitas yaitu penurunan pada harga saham [1]. Efek asimetris terjadi ketika pengaruh terhadap volatilitas saham berbeda antara good news dan bad news. Perbedaan yang dimaksud adalah bad news memiliki pengaruh yang lebih kuat terhadap peningkatan volatilitas dibandingkan good news.

Keberadaan pengaruh asimetris dilihat dari korelasi antara $\varepsilon_{t}^{2}$ (standar residual kuadrat model Box Jenkins) dengan $\varepsilon_{t-s}$ (standar residual model GARCH) pada cross correlogram [9]. Korelasi silang sampel dari dua runtun waktu dirumuskan sebagai berikut [10].

$$
r_{x y}(k)=\frac{c_{x y}(k)}{s_{x} s_{y}}, k=0, \pm 1, \pm 2, \ldots,
$$

dimana

$$
c_{x y}(k)= \begin{cases}\sum_{t=1}^{n-k} \frac{\left(\left(x_{t}-\bar{x}\right)\left(y_{t+k}-\bar{y}\right)\right)}{n}, & k \geq 0 \\ \sum_{t=1-k}^{n} \frac{\left(\left(x_{t}-\bar{x}\right)\left(y_{t+k}-\bar{y}\right)\right)}{n}, & k<0\end{cases}
$$

dengan $x$ adalah standar residual kuadrat model Box Jenkins $\left(\varepsilon_{t}^{2}\right), y$ adalah standar residual model GARCH $\left(\varepsilon_{t-s}\right), s_{x}$ dan $s_{y}$ adalah standar deviasi dari $x$ dan $y, k$ adalah lag dan $n$ adalah jumlah observasi. Kondisi bad news dan good news memberi pengaruh asimetris terhadap volatilitasnya jika terdapat lag yang keluar dari batas selang kepercayaan $\pm 1,96(1 / \sqrt{n})[9]$.

\section{MODEL THRESHOLD GENERALIZED AUTOREGRESSIVE CONDITIONAL HETEROSCEDASTICITY (TGARCH)}

Model Threshold Generalized Autoregressive Conditional Heteroscedasticity (TGARCH) merupakan salah satu pengembangan model GARCH [3]. Model TGARCH mampu menangkap kejadian ketidaksimetrisan good news dan bad news dalam volatilitas. Bentuk umum dari model $\operatorname{TGARCH}(u, s)$ adalah

$$
\sigma_{t}^{2}=\omega+\sum_{i=1}^{u}\left(\alpha_{i}+\gamma_{i} I_{t-i}\right) \varepsilon_{t-i}^{2}+\sum_{j=1}^{s} \beta_{j} \sigma_{t-j}^{2}
$$


dengan $\omega$ adalah konstanta, $a_{i}$ adalah parameter $\mathrm{ARCH}, \beta_{i}$ adalah parameter $\mathrm{GARCH}, \varepsilon_{t-i}$ adalah residual, dan $\gamma_{i}$ adalah konstanta asimetris. $I_{t-l}$ merupakan variabel dummy bernilai 1 ketika $\varepsilon_{t-1}<0$ dan bernilai 0 ketika $\varepsilon_{t-1} \geq 0$.

\section{STUDI KASUS}

Data yang digunakan pada penelitian ini merupakan return dari Indeks Harga Saham Gabungan (IHSG) mingguan dari 8 Februari 2009 sampai dengan 10 Februari 2019 sebanyak 518 observasi [11]. Berikut ini statistik deskriptif dari return IHSG.

\begin{tabular}{lr}
\multicolumn{1}{c}{ Tabel 1 Statistik Deskriptif } & Return IHSG \\
\hline Statistik & \multicolumn{1}{c}{ Nilai } \\
\hline Mean & 0,003028 \\
Maksimum & 0,109147 \\
Minimum & $-0,112722$ \\
Standar Deviasi & 0,023876 \\
Jumlah Observasi & 518
\end{tabular}

Nilai maksimum return saham sebesar 0,109147 dan nilai minimum sebesar -0,112722. Hasil tersebut menunjukkan bahwa besarnya nilai return saham dalam penelitian ini berkisar antara $-0,112722$ sampai 0,109147 .

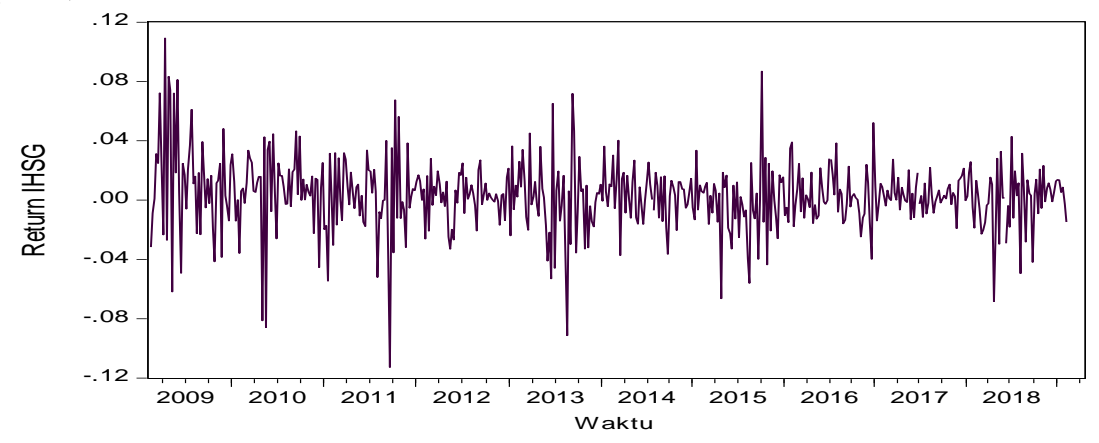

Gambar 1 Grafik Data Return

Pada Gambar 1 terlihat bahwa pada pertengahan tahun 2011 sampai dengan akhir tahun 2011 pergerakan return cenderung lebih naik atau turun secara drastis dibandingkan tahun lainnya. Hal ini dikarenakan tahun 2011 merupakan puncak krisis Eropa yang menjadi penyebab turunnya harga saham di banyak negara termasuk di Indonesia. Dalam teori keuangan peristiwa ini dinamakan volatility clustering. Pengujian stasioneritas data return IHSG dilakukan dengan Augmented DickeyFuller Unit Root Test, diperoleh nilai $t$ sebesar -25,57567 dengan probabilitas dari $t$ adalah 0,000. Dengan taraf signifikansi $\alpha(0,05)$ maka dapat disimpulkan bahwa return saham bersifat stasioner. Pembentukan model Box Jenkins dari data return ditentukan melalui ACF dan PACF yang disajikan dalam Gambar 2.

\begin{tabular}{|c|c|c|c|c|c|c|}
\hline \multicolumn{7}{|c|}{$\begin{array}{l}\text { Sample: } 2 / 08 / 20092 / 10 / 2019 \\
\text { Included observations: } 518\end{array}$} \\
\hline Autocorrelation & Partial Correlation & & $A C$ & PAC & Q-Stat & Prob \\
\hline ㄷ. & 다 & & -0.135 & -0.135 & 9.5147 & 0.002 \\
\hline 4 & in & 2 & 0.082 & 0.065 & 13.011 & 0.001 \\
\hline if, & i & 3 & 0.016 & 0.036 & 13.152 & 0.004 \\
\hline in & 1 & 4 & -0.045 & -0.045 & 14.228 & 0.007 \\
\hline קטי & ק' & 5 & 0.118 & 0.105 & 21.544 & 0.001 \\
\hline 111 & 19 & 6 & 0.017 & 0.053 & 21.696 & 0.001 \\
\hline 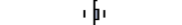 & 17 & 7 & 0.034 & 0.029 & 22.317 & 0.002 \\
\hline 1 & 11 & 8 & 0.002 & -0.001 & 22.320 & 0.004 \\
\hline 1. & 1. & $\mathrm{~s}$ & -0.002 & 0.002 & 22.321 & 0.008 \\
\hline i & 1 & 10 & 0.044 & 0.034 & 23.336 & 0.010 \\
\hline 1 & 1 & 11 & -0.002 & 0.001 & 23.339 & 0.016 \\
\hline יני & יוקי & 12 & 0.042 & 0.030 & 24.290 & 0.019 \\
\hline 1 & ' 1 & 13 & -0.005 & 0.001 & 24.302 & 0.028 \\
\hline 1 & $1 / 1$ & 14 & 0.004 & 0.000 & 24.312 & 0.042 \\
\hline י & 1,11 & 15 & 0.028 & 0.020 & 24.734 & 0.054 \\
\hline 5 & p & 16 & 0.078 & 0.087 & 27.969 & 0.032 \\
\hline 1 & $\sqrt{1}$ & 17 & -0.052 & -0.047 & 29.427 & 0.031 \\
\hline 1] 1 & 1 & 18 & -0.003 & -0.032 & 29.432 & 0.043 \\
\hline in & 10 & 15 & -0.027 & -0.028 & 29.837 & 0.054 \\
\hline
\end{tabular}

Gambar 2 ACF dan PACF dari Return IHSG 
Nilai ACF dan PACF yang berada diluar selang kepercayaan adalah pada lag 1 dengan selang kepercayaan yaitu $\pm 0,086117$. Jadi terdapat 3 model yang diuji untuk melihat model terbaik yaitu AR(1), MA(1) dan ARMA(1,1). Estimasi parameter model Box Jenkins disajikan dalam Tabel 2.

Tabel 2 Estimasi Parameter Model Box Jenkins

\begin{tabular}{ccccc}
\hline Model & Koefisien & Probabilitas & AIC & SC \\
\hline \multirow{2}{*}{ AR(1) } & $0,003^{*}$ & 0,001 & $\mathbf{- 4 , 6 4 0 7 5 4}$ & $\mathbf{- 4 , 6 1 6 1 4 0}$ \\
& $-0,136^{*}$ & 0,000 & & \\
\hline \multirow{2}{*}{ MA(1) } & $0,003^{*}$ & 0,001 & $-4,638311$ & $-4,613697$ \\
& $-0,118^{*}$ & 0,000 & & \\
\hline \multirow{2}{*}{ ARMA(1,1) } & $0,003^{*}$ & 0,001 & & $-4,606349$ \\
& $-0,366$ & 0,051 & $-4,639168$ & \\
\hline
\end{tabular}

*koefisien yang signifikan

Berdasarkan Tabel 2 disimpulkan bahwa $\operatorname{ARMA}(1,1)$ tidak signifikan karena terdapat nilai probabilitas koefisien yang lebih besar dari $\alpha(0,05)$. Model Box Jenkins terbaik adalah model AR(1) karena memiliki AIC dan SC terkecil. Heteroskedastisitas pada return saham dapat dilihat menggunakan uji ARCH-LM. Return saham dikatakan memiliki heteroskedastisitas jika nilai probabilitas lebih kecil dari $\alpha(0,05)$. Uji ARCH-LM disajikan dalam Tabel 3.

Tabel 3 Uji ARCH-LM

\begin{tabular}{cc}
\hline F-statistic & Probabilitas \\
\hline 8,1039 & 0,0046
\end{tabular}

Pada Tabel 3 terlihat bahwa nilai probabilitas $F$ lebih kecil dari $\alpha(0,05)$ sehingga dapat disimpulkan bahwa terdapat heteroskedastisitas pada return saham. Data return saham yang memiliki heteroskedastisitas selanjutnya dimodelkan dalam model $\operatorname{GARCH}$ yaitu model $\operatorname{GARCH}(1,1)$, $\operatorname{GARCH}(1,2), \operatorname{GARCH}(2,1)$ atau $\operatorname{GARCH}(2,2)$. Estimasi parameter model GARCH disajikan dalam Tabel 4.

Tabel 4 Estimasi Parameter Model GARCH

\begin{tabular}{|c|c|c|c|c|c|}
\hline Model GARCH & Parameter & Koefisien & Probabilitas & AIC & SC \\
\hline \multirow{3}{*}{$\operatorname{GARCH}(1,1)$} & $\omega$ & $5,08 \times 10^{-5^{*}}$ & 0,000 & \multirow{3}{*}{$-4,8187$} & \multirow{3}{*}{$-4,7777$} \\
\hline & $\alpha_{1}$ & $0,216^{*}$ & 0,000 & & \\
\hline & $\beta_{1}$ & $0,705^{*}$ & 0,000 & & \\
\hline \multirow{4}{*}{$\operatorname{GARCH}(2,1)$} & $\omega$ & $3,83 \times 10^{-5^{*}}$ & 0,003 & \multirow{4}{*}{$-4,8199$} & \multirow{4}{*}{$-4,7707$} \\
\hline & $\alpha_{1}$ & $0,33^{*}$ & 0,000 & & \\
\hline & $\alpha_{2}$ & $-0,151$ & 0,452 & & \\
\hline & $\beta_{1}$ & $0,765^{*}$ & 0,000 & & \\
\hline \multirow{4}{*}{$\operatorname{GARCH}(1,2)$} & $\omega$ & $5,8 \times 10^{-5 *}$ & 0,004 & \multirow{4}{*}{$-4,8164$} & \multirow{4}{*}{$-4,7672$} \\
\hline & $\alpha_{1}$ & $0,253^{*}$ & 0,000 & & \\
\hline & $\beta_{1}$ & $0,509^{*}$ & 0,031 & & \\
\hline & $\beta_{2}$ & 0,149 & 0,406 & & \\
\hline \multirow{5}{*}{$\operatorname{GARCH}(2,2)$} & $\omega$ & $2,4 \times 10^{-5}$ & 0,276 & \multirow{5}{*}{$-4,8183$} & \multirow{5}{*}{$-4,7609$} \\
\hline & $\alpha_{1}$ & $0,336^{*}$ & 0,000 & & \\
\hline & $\alpha_{2}$ & $-0,225^{*}$ & 0,036 & & \\
\hline & $\beta_{1}$ & $1,038^{*}$ & 0,004 & & \\
\hline & $\beta_{2}$ & $-0,186$ & 0,447 & & \\
\hline
\end{tabular}

*koefisien yang signifikan 
Berdasarkan Tabel 4 maka dapat disimpulkan hanya terdapat satu model yang semua koefisiennya signifikan yaitu model $\operatorname{GARCH}(1,1)$, selain itu model tersebut juga memiliki nilai SC terkecil sehingga disimpulkan model terbaik GARCH adalah model $\operatorname{GARCH}(1,1)$. Uji pengaruh asimetris dilakukan dengan cara melakukan korelasi silang pada standar residual kuadrat model AR(1) dengan standar residual model GARCH(1,1) yang disajikan pada Gambar 4.

\begin{tabular}{|c|c|c|c|c|}
\hline \multicolumn{5}{|c|}{ Cross Correlogram of RESIDUAL2_AR1 and RESIDUAL_GARCH11 } \\
\hline RESIDUAL2_AR1,RESID... & RESIDUAL2_AR1,RESID... & $\mathbf{i}$ & lag & lead \\
\hline 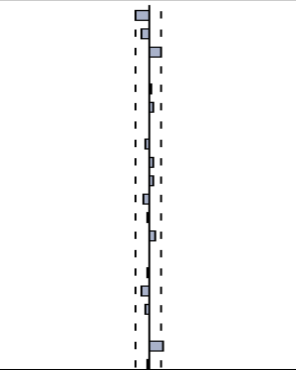 & 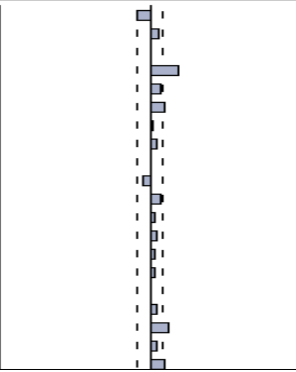 & $\begin{array}{r}0 \\
1 \\
2 \\
3 \\
4 \\
5 \\
6 \\
7 \\
8 \\
9 \\
10 \\
11 \\
12 \\
13 \\
14 \\
15 \\
16 \\
17 \\
18 \\
19\end{array}$ & $\begin{array}{r}-0.0943 \\
-0.0520 \\
0.0840 \\
0.0106 \\
0.0233 \\
0.0292 \\
0.0018 \\
-0.0170 \\
0.0313 \\
0.0354 \\
-0.0407 \\
-0.0132 \\
0.0474 \\
0.0142 \\
-0.0078 \\
-0.0457 \\
-0.0240 \\
0.0110 \\
0.1010 \\
-0.0019\end{array}$ & $\begin{array}{r}-0.0943 \\
0.0651 \\
0.0066 \\
0.1993 \\
0.0782 \\
0.1013 \\
0.0192 \\
0.0506 \\
0.0131 \\
-0.0555 \\
0.0787 \\
0.0395 \\
0.0431 \\
0.0258 \\
0.0370 \\
0.0125 \\
0.0538 \\
0.1308 \\
0.0414 \\
0.0994\end{array}$ \\
\hline
\end{tabular}

Gambar 4 Cross Correlogram Standar Residual Kuadrat Model AR(1) dengan Standar Residual Model GARCH(1,1)

Pada Gambar 4 terdapat lag yang keluar dari garis yaitu lag keempat sehingga dapat disimpulkan bahwa kondisi bad news dan good news memberi pengaruh asimetris terhadap volatilitas. Jika terdapat pengaruh asimetris terhadap volatilitas maka volatilitas dimodelkan menggunakan model TGARCH. Pengujian signifikansi dari model dengan orde $u$ dan $s$ dengan menggunakan uji signifikansi parameter dengan $\alpha(0,05)$. Koefisien berpengaruh secara signifikan terhadap model jika probabilitas $<\alpha$. Estimasi parameter model TGARCH disajikan pada Tabel 5.

Tabel 5 Estimasi Parameter Model TGARCH

\begin{tabular}{|c|c|c|c|c|c|}
\hline Model TGARCH & Parameter & Koefisien & Probabilitas & AIC & SC \\
\hline \multirow{4}{*}{$\operatorname{TGARCH}(1,1)$} & $\omega$ & $5,06 \times 10^{-5^{*}}$ & 0,000 & \multirow{4}{*}{$-4,8201$} & \multirow{4}{*}{$-4,7709$} \\
\hline & $\alpha_{1}$ & $0,158^{*}$ & 0,000 & & \\
\hline & $\gamma_{1}$ & $0,116^{*}$ & 0,045 & & \\
\hline & $\beta_{1}$ & $0,706^{*}$ & 0,000 & & \\
\hline \multirow{5}{*}{ TGARCH $(1,2)$} & $\omega$ & $6,00 \times 10^{-5^{*}}$ & 0,002 & \multirow{5}{*}{$-4,8188$} & \multirow{5}{*}{$-4,7614$} \\
\hline & $\alpha_{1}$ & $0,185^{*}$ & 0,001 & & \\
\hline & $\gamma_{1}$ & $0,152^{*}$ & 0,044 & & \\
\hline & $\beta_{1}$ & $0,454^{*}$ & 0,024 & & \\
\hline & $\beta_{2}$ & 0,193 & 0,22 & & \\
\hline \multirow{6}{*}{$\operatorname{TGARCH}(2,1)$} & $\omega$ & $3,24 \times 10^{-5 *}$ & 0,003 & \multirow{6}{*}{$-4,8271$} & \multirow{6}{*}{$-4,7615$} \\
\hline & $\alpha_{1}$ & 0,072 & 0,344 & & \\
\hline & $\alpha_{2}$ & 0,023 & 0,760 & & \\
\hline & $\gamma_{1}$ & $0,431^{*}$ & 0,000 & & \\
\hline & $\gamma_{2}$ & $-0,334^{*}$ & 0,002 & & \\
\hline & $\beta_{1}$ & $0,804^{*}$ & 0,000 & & \\
\hline \multirow{7}{*}{ TGARCH $(2,2)$} & $\omega$ & $1,74 \times 10^{-5^{*}}$ & 0,045 & \multirow{7}{*}{$-4,8265$} & \multirow{7}{*}{$-4,7527$} \\
\hline & $\alpha_{1}$ & 0,073 & 0,331 & & \\
\hline & $\alpha_{2}$ & $-0,022$ & 0,778 & & \\
\hline & $\gamma_{1}$ & $0,471^{*}$ & 0,000 & & \\
\hline & $\gamma_{2}$ & $-0,416^{*}$ & 0,001 & & \\
\hline & $\beta_{1}$ & $1,061^{*}$ & 0,000 & & \\
\hline & $\beta_{2}$ & $-0,168$ & 0,106 & & \\
\hline
\end{tabular}

*koefisien yang signifikan 
Berdasarkan Tabel 5 setiap nilai koefisien $\omega$ untuk semua model signifikan. Nilai koefisien $\beta_{2}$ tidak signifikan pada model TGARCH $(1,2)$. Selain itu, nilai koefisien $\alpha_{1}$ dan $\alpha_{2}$ juga tidak signifikan pada model TGARCH(2,1), sedangkan pada model TGARCH(2,2) koefisien $\alpha_{1}, \alpha_{2}$, dan $\beta_{2}$. Pada Tabel 5 nilai AIC terkecil terdapat pada model $\operatorname{TGARCH}(2,1)$ sedangkan nilai SC terkecil terdapat pada model TGARCH(1,1). Berdasarkan uji signifikansi, nilai AIC dan SC terkecil model yang memenuhi keduanya adalah model TGARCH $(1,1)$. Oleh karena itu model terbaik untuk pemodelan volatilitas adalah model TGARCH $(1,1)$. Bentuk model TGARCH $(1,1)$ sebagai berikut.

$$
\sigma_{t}^{2}=0,0000506+0,158 \varepsilon_{t-1}^{2}+0,116 \varepsilon_{t-1}^{2} I_{t-1}+0,706 \sigma_{t-1}^{2}
$$

Model yang layak digunakan adalah model yang memiliki white noise, yaitu model yang tidak memiliki korelasi pada residual. Residual model $\operatorname{TGARCH}(1,1)$ diuji untuk melihat adanya white noise yang disajikan pada Gambar 5.

\begin{tabular}{|c|c|c|c|c|c|c|}
\hline \multirow[b]{2}{*}{ Autocorrelation } & \multicolumn{5}{|c|}{ Correlogram of Standardized Residuals } & \multirow[b]{2}{*}{ Prob* } \\
\hline & Partial Correlation & & $A C$ & PAC & Q-Stat & \\
\hline 1 1 & ומן ו & 1 & 0.028 & 0.028 & 0.4148 & \\
\hline $1 \sqrt{11}$ & 1 & 2 & 0.030 & 0.029 & 0.8815 & 0.348 \\
\hline 11 & 11 & 3 & 0.023 & 0.022 & 1.1611 & 0.560 \\
\hline $1 \sqrt{1}$ & 1,1 & 4 & -0.006 & -0.008 & 1.1778 & 0.758 \\
\hline ip & ip & 5 & 0.069 & 0.068 & 3.6964 & 0.449 \\
\hline $1 \sqrt{1}$ & 111 & 6 & 0.024 & 0.020 & 4.0046 & 0.549 \\
\hline $1 / 17$ & 1,11 & 7 & 0.027 & 0.022 & 4.3907 & 0.624 \\
\hline 1 & 1 & 8 & -0.025 & -0.031 & 4.7192 & 0.694 \\
\hline 11 & 1) & 9 & -0.017 & -0.017 & 4.8769 & 0.771 \\
\hline 111 & $1 / 1$ & 10 & 0.026 & 0.023 & 5.2361 & 0.813 \\
\hline 11 & 11 & 11 & -0.013 & -0.015 & 5.3288 & 0.868 \\
\hline 1$]$ & 11 & 12 & 0.003 & -0.001 & 5.3328 & 0.914 \\
\hline 111 & 111 & 13 & 0.016 & 0.018 & 5.4719 & 0.940 \\
\hline 1 & 1 & 14 & -0.032 & -0.029 & 6.0100 & 0.946 \\
\hline 1) & יד & 15 & 0.043 & 0.043 & 7.0066 & 0.934 \\
\hline 13 & 13 & 16 & 0.073 & 0.074 & 9.9006 & 0.826 \\
\hline$\sqrt{1}$ & $\sqrt{1}$ & 17 & -0.085 & -0.093 & 13.767 & 0.616 \\
\hline 1. & 1. & 18 & -0.041 & -0.044 & 14.655 & 0.620 \\
\hline 1 & 10 & 19 & -0.063 & -0.056 & 16.804 & 0.537 \\
\hline
\end{tabular}

Gambar 5 Correlogram Residual Model TGARCH(1,1)

Model TGARCH $(1,1)$ bersifat white noise karena pada Gambar 5 tidak ada lag yang melewati garis sehingga dapat disimpulkan bahwa tidak terdapat korelasi residual pada model. Jika tidak terdapat korelasi pada residual model $\operatorname{TGARCH}(1,1)$ maka model $\operatorname{TGARCH}(1,1)$ layak digunakan. Selanjutnya model TGARCH(1,1) digunakan untuk meramalkan volatilitas saham dari tanggal 17 Februari 2019 sampai dengan 21 April 2019 yang ditunjukkan dalam Tabel 6.

Tabel 6 Hasil Peramalan Volatilitas 10 Periode Ke Depan

\begin{tabular}{cc}
\hline Tanggal & Peramalan Volatilitas \\
\hline $17 / 2 / 2019$ & 0,000279 \\
$24 / 2 / 2019$ & 0,000308 \\
$03 / 3 / 2019$ & 0,000334 \\
$10 / 3 / 2019$ & 0,000359 \\
$17 / 3 / 2019$ & 0,000381 \\
$24 / 3 / 2019$ & 0,000402 \\
$31 / 3 / 2019$ & 0,000420 \\
$07 / 4 / 2019$ & 0,000438 \\
$14 / 4 / 2019$ & 0,000454 \\
$21 / 4 / 2019$ & 0,000469 \\
\hline
\end{tabular}

Pada Tabel 6 menyajikan hasil peramalan volatilitas IHSG menggunakan model $\operatorname{TGARCH}(1,1)$. Berdasarkan Tabel 6 pergerakan pada peramalan volatilitas IHSG untuk sepuluh periode ke depan mengalami peningkatan dari periode pertama sampai dengan periode ke sepuluh. 


\section{KESIMPULAN}

Berdasarkan penelitian yang telah dilakukan, diperoleh kesimpulan bahwa model terbaik untuk memodelkan volatilitas IHSG adalah model TGARCH(1,1). Berikut ini adalah bentuk model $\operatorname{TGARCH}(1,1)$ pada return saham.

$$
\sigma_{t}^{2}=0,0000506+0,158 \varepsilon_{t-1}^{2}+0,116 \varepsilon_{t-1}^{2} I_{t-1}+0,706 \sigma_{t-1}^{2}
$$

Hasil peramalan volatilitas yang diperoleh dari tanggal 17 Februari 2019 sampai dengan 21 April 2019 mengalami peningkatan sebesar 0,000015 sampai dengan 0,000029.

\section{DAFTAR PUSTAKA}

[1]. Sari, L. K., Achsani, N. A., dan Sartono, B. Pemodelan Volatilitas Return Saham: Studi Kasus Pasar Saham Asia. Jurnal Ekonomi dan Pembangunan Indonesia. 2017. 18(1):35-52.

[2]. Bollerslev, T. Generalized Autoregressive Conditional Heteroskedasticity. Journal of Econometric. 1986. 31(3):307-327.

[3]. Glosten, L. R., Jagannathan, R., dan Runkle, D. E. On the Relation between the Expected Value and the Volatility of the Nominal Excess Return on Stocks. The Journal of Finance. 1993. 48(5):1779-1801.

[4]. Chen, W. Y dan Lian, K. K. A Comparison of Forecasting Models for ASEAN Equity Markets. Sunway Academic Journal. 2005. 2(2):1-12.

[5]. Sova, M. Pengaruh Ratio Leverage Terhadap Volatilitas Saham pada Industri Barang Konsumsi di Bursa Efek Indonesia Tahun 2004-2008. E-Journal Widya Ekonomika. 2013. 1(1):7-11.

[6]. Tsay, R. S. Analysis of Financial Time Series. New Jersey: John Wiley \& Sons, Inc; 2010.

[7]. Azzam, I. The Effect of Model-Selection Uncertainty on Autoregressive Models Estimates. International Research Journal of Finance and Economics. 2007. 2(11):80-93.

[8]. Rosadi, D. Ekonometrika dan Analisis Runtun Waktu Terapan dengan Eviews. Yogyakarta: ANDI; 2012.

[9]. Elvitra, C. W., Warsito, B., dan Hoyyi, A. Metode Peramalan dengan Menggunakan Model Volatilitas Asymmetric Power ARCH (APARCH). Jurnal Gaussian. 2013. 2(4):289-300.

[10].Wei, W. W. S. Time Series Analysis: Univariate and Multivariate Methods. New York: Pearson; 2006.

[11].https://finance.yahoo.com/quote/\%5EJKSE/history?period1 $=1234026000 \&$ period2 $=1549731600$ \&interval $=1 \mathrm{wk} \&$ filter $=$ history \& frequency $=1 \mathrm{wk},(10$ Februari 2019).

ERVINA

DADAN KUSNANDAR

NURFITRI IMRO’AH
: Jurusan Matematika FMIPA UNTAN, Pontianak ervina.protak@gmail.com

: Jurusan Matematika FMIPA UNTAN, Pontianak dkusnand@untan.ac.id

: Jurusan Matematika FMIPA UNTAN, Pontianak nurfitriimroah@math.untan.ac.id 